\title{
Correction to: Molecular basis and outcomes of a typical haemolytic uraemic syndrome in Czech children
}

\author{
Šárka Štolbová ${ }^{*}$ Martin Bezdíčka ${ }^{1} \cdot$ Tomas Seeman $^{1} \cdot$ Zoltán Prohászka $^{2} \cdot$ Dorottya Csuka $^{2} \cdot$ Ingrid Hrachovinová $^{3}$. \\ Jan Burkert ${ }^{4}$ - Naděžda Šimánková ${ }^{1}$ Štěpánka Průhová ${ }^{~} \cdot$ Jakub Zieg $^{1}$
}

Published online: 11 January 2022

(c) Springer-Verlag GmbH Germany, part of Springer Nature 2021

\section{Correction to: European Journal of Pediatrics (2020) 179:1739-1750 https://doi.org/10.1007/s00431-020-03666-9}

The author Tomas Seeman has been omitted in the authorship group however it was realized that he had contributed significantly to above the article. All authors including the reader have agreed to add him.

The original article has been corrected.

Publisher's Note Springer Nature remains neutral with regard to jurisdictional claims in published maps and institutional affiliations.

The original article can be found online at https://doi.org/10.1007/ s00431-020-03666-9.

Martin Bezdíčka

martin.bezdicka@fnmotol.cz

Šárka Štolbová

sarka.stolbova@fnmotol.cz

Zoltán Prohászka

prohaszka.zoltan@med.semmelweis-univ.hu

Dorottya Csuka

csuka.dorottya@med.semmelweis-univ.hu

Ingrid Hrachovinová

Ingrid.Hrachovinova@uhkt.cz

Jan Burkert

Jan.Burkert@fnmotol.cz

Naděžda Šimánková

Nadezda.Simankova@fnmotol.cz

Štěpánka Průhová

Stepanka.Pruhova@fnmotol.cz
Jakub Zieg

jakub.zieg@fnmotol.cz

1 Department of Paediatrics, 2nd Faculty of Medicine, Charles University in Prague, and Motol University Hospital, Prague, Czech Republic

2 3rd Department of Medicine and MTA-SE Research Group of Immunology and Haematology, Hungarian Academy of Sciences and Semmelweis University, Budapest, Hungary

3 Institute of Haematology and Blood Transfusion, Prague, Czech Republic

4 Department of Cardiovascular Surgery, 2nd Faculty of Medicine, Charles University in Prague, and Motol University Hospital, Prague, Czech Republic 